\title{
Environmental photochemical fate and UVC degradation of sodium levothyroxine in aqueous medium
}

\author{
Marcela Prado Silva Parizi ${ }^{1}$ (1) - Arlen Mabel Lastre Acosta ${ }^{2} \cdot$ Hamilton Mitsugu Ishiki $^{3} \cdot$ Renata Calciolari Rossi $^{3}$. \\ Renata Cristina Mafra ${ }^{3} \cdot$ Antonio Carlos Silva Costa Teixeira $^{2}$
}

Received: 30 January 2018 / Accepted: 3 August 2018 / Published online: 14 August 2018

(C) Springer-Verlag GmbH Germany, part of Springer Nature 2018

\begin{abstract}
The synthetic hormone sodium levothyroxine (LTX) is one of the most prescribed drugs in the world and the most effective in hypothyroidism treatment. The presence of LTX in the environment has become a matter of major concern due to the widespread use of this hormone and by the fact that it is only partially removed in conventional water and sewage treatment plants. However, information regarding the photochemical fate of this hormone in environmental or engineered systems is scarce in the literature. In this work, the sunlight-driven direct and indirect LTX degradation was investigated by determining the photolysis quantum yield, $\Phi_{\mathrm{LTX}}=3.80( \pm 0.02) \times 10^{-5}$, as well as the second-order kinetic constants of the reactions with hydroxyl radicals, $k_{\mathrm{LTX}, \cdot \mathrm{OH}}=1.50( \pm 0.01) \times 10^{10} \mathrm{~L} \mathrm{~mol}^{-1} \mathrm{~s}^{-1}$ and singlet oxygen, $k_{\mathrm{LTX}, 1 \mathrm{O} 2}=1.47( \pm 0.66) \times 10^{8} \mathrm{~L} \mathrm{~mol}^{-1} \mathrm{~s}^{-1}$. Mathematical simulations indicate that LTX photodegradation is favored in shallow, nitrite-rich, and dissolved organic matter (DOM)-poor environments, with LTX half-life times varying from less than 10 days to about 80 days. LTX removals of 85 and $95 \%$ were achieved by UVC photolysis and $\mathrm{UVC} / \mathrm{H}_{2} \mathrm{O}_{2}$ after $120 \mathrm{~min}$, respectively. Three transformation products, triiodothyronine, diiodothyronine, and diiodotyrosine, were identified during LTX degradation by the UVC-based processes studied. The results herein regarding photo-induced kinetics coupled with environmental fate simulations may help evaluate LTX persistence and also the design of water and wastewater treatment processes.
\end{abstract}

Keywords Sodium levothyroxine $\cdot$ Environmental photochemical fate $\cdot$ Advanced oxidation processes $\cdot$ Endocrine disruptors Reactive oxygen species $\cdot$ Mathematical simulations

Responsible editor: Suresh Pillai

Electronic supplementary material The online version of this article (https://doi.org/10.1007/s11356-018-2907-0) contains supplementary material, which is available to authorized users.

Marcela Prado Silva Parizi marpradosilva@hotmail.com

1 Energy Engineering Department, São Paulo State University (UNESP), Barrageiros Av. 1881, Rosana, SP, Brazil

2 Research Group in Advanced Oxidation Processes, Chemical Systems Engineering Center, Department of Chemical Engineering, University of São Paulo, Av. Prof. Luciano Gualberto, tr. 3, 380, São Paulo, SP, Brazil

3 Environment and Regional Development, University of Western São Paulo (Unoeste), Presidente Prudente, SP, Brazil

\section{Introduction}

There is great concern about the presence of endocrine disruptors (EDs) in the aquatic environment, due to the potential of these micro-pollutants to interfere with body systems, resulting in adverse neurological, immune, developmental, and reproductive effects in both humans and wildlife (Bila and Dezotti 2003). Different pollutants have been classified as EDs, including pesticides, personal care products, and especially pharmaceuticals and hormones (Bila and Dezotti 2003). An example is the synthetic hormone sodium levothyroxine-T4 (LTX, Fig. 1) (Svanfelt et al. 2010), the most effective drug in the treatment of hypothyroidism (Cappelli et al. 2013). LTX has important roles in many physiological processes, e.g., embryonic development, cell 
<smiles>N[C@@H](Cc1cc(I)c(Oc2cc(I)c(O)c(I)c2)c(I)c1)C(=O)O[Na]</smiles>

Fig. 1 Molecular structure of sodium levothyroxine-T4

differentiation, metabolism, and the regulation of cell proliferation (Svanfelt et al. 2010). Owing to the high prevalence of hypothyroidism, LTX is one of the most prescribed medications (Bolk et al. 2010), representing the fourth most common medication dispensed in the USA in the last few years (Cappelli et al. 2013); in Brazil, it was the twelfth bestselling drug in 2016 according to the Brazilian Health Regulatory Agency (ANVISA 2017).

Dong et al. (2013) propose classifying pharmaceuticals that show potential human and ecological health risks according to a simple prioritization approach based on the number of prescriptions and toxicity information, accounting for metabolism and recalcitrance in wastewater treatment. According to this approach, LTX received the highest scores among the top 200 prescribed drugs in the USA in 2009, suggesting the need for studies to evaluate its degradation in environmental and in engineered treatment systems.

Similar to other pharmaceuticals and hormones, LTX enters the environment primarily by excretion from patients into domestic sewage (Kostich and Lazorchak 2008). Twenty to $40 \%$ of the typical LTX dose is excreted in urine and/or feces and then dispersed into domestic sewage (Ianiro et al. 2014). However, water and sewage treatment plants only partially eliminate this compound, accounting for less than $3 \%$ removal (Dong et al. 2013). LTX has been found in sewage treatment plants influent and effluents in the range $3.1-55.0 \mathrm{mg} \mathrm{L}^{-1}$ and 7.3-37.6 $\mathrm{mg} \mathrm{L}^{-1}$, respectively (Zacarias et al. 2017). LTX has therefore been recognized as a contaminant of environmental concern (Kostich and Lazorchak 2008).

Considering that drugs are designed to target specific metabolic and biological pathways, there is concern that some pharmaceutical compounds may disrupt key processes in sensitive, non-target organisms, including certain human populations such as children and pregnant women, even at trace environmental concentration levels (ng L ${ }^{-1}-\mu \mathrm{g} \mathrm{L}^{-1}$ ), which are clearly much lower than the therapeutically effective doses (Dong et al. 2013). For that reason, understanding the destination and transport processes of micro-pollutants such as LTX in the environment is essential to assess their potential impact. Furthermore, it is necessary to develop effective water and wastewater treatment techniques for LTX removal.

Photochemical degradation mediated by solar radiation plays an important role in the fate of emerging contaminants in natural waters (Boreen et al. 2004; Lam and Mabury 2005).
Photo-induced processes may represent major removal pathways, especially for pollutants refractory to biological degradation (Vione et al. 2010), involving both direct photolysis and indirect photodegradation (Laurentiis et al. 2012). The latter mechanism is mediated by reactive oxygen species (ROS) such as singlet oxygen $\left({ }^{1} \mathrm{O}_{2}\right)$ and hydroxyl radicals ( $\mathrm{OH})$.

Svanfelt et al. (2011) studied LTX photodegradation under UV light from a fluorescent source emitting in the range $300-400 \mathrm{~nm}$ (low-wavelength region of sunlight). The authors identified two major byproducts and pointed out that direct photo-transformation is of importance when assessing the fate of LTX in the aquatic environment. Abdallah and Mohamed (2016) investigated the factors affecting the photo and thermal LTX stability and concluded that the hormone undergoes significant photodecomposition under exposure to sunlight, while temperature has a negligible effect. The authors also showed that levothyroxine sodium is more stable in acidic medium. Nevertheless, there are no studies in the literature related to the LTX photochemical environmental fate, considering direct photolysis and indirect photodegradation.

This study is aimed at understanding the photochemical fate of LTX in surface waters. Kinetic rate constants of LTX degradation by reactive oxygen species $\left({ }^{\circ} \mathrm{OH}\right.$ and ${ }^{1} \mathrm{O}_{2}$ ) were experimentally determined along with its photolysis quantum yield, which are reported here for the first time. The goal was to assess the expected persistence of LTX in surface waters by investigating its sunlight-driven direct and indirect degradation. The conditions that favor or hamper LTX photodegradation in natural water bodies are detailed based on our experimental results and mathematical simulations. Finally, LTX degradation by UVC photolysis $(254 \mathrm{~nm})$, and by the advanced oxidation process $\mathrm{UVC} / \mathrm{H}_{2} \mathrm{O}_{2}$ is also discussed.

\section{Materials and methods}

\section{Chemicals}

All the solutions were prepared using Milli-Q water. Levothyroxine (LTX) sodium hydrate (3,3',5,5'-tetraiodo-Lthyronine monosodium salt hydrate, $\mathrm{C}_{15} \mathrm{H}_{10} \mathrm{I}_{4} \mathrm{NNaO}_{4} \cdot \mathrm{xH}_{2} \mathrm{O}$, CAS 25416-65-3) was purchased from Sigma-Aldrich and used in liquid chromatography (HPLC) analysis and in the photochemical experiments. Hydrogen peroxide, methylene blue, furfuryl alcohol (FFA), and para-chlorobenzoic acid (pCBA) were all of reagent grade purity and also purchased from Sigma-Aldrich. For HPLC analysis, Honeywell high purity acetonitrile, methanol, phosphoric acid (100\%), and formic acid (100\%) were used. 


\section{Equipment and procedures}

\section{Molar absorption coefficient spectrum}

The spectral molar absorption coefficient $\left(\varepsilon_{\lambda}\right)$ of LTX was measured using a Varian Cary 100 Bio spectrophotometer, equipped with a $1-\mathrm{cm}$ path length quartz cuvette, according to a well-known procedure (Harris 2003).

\section{Photodegradation experiments under simulated solar light}

Photodegradation experiments were performed using a Model 91160 Oriel solar simulator equipped with a $450-\mathrm{W}$ xenon lamp and an AM 1.5 global filter (Newport Corp., Oriel Instruments), providing $68 \mathrm{~W} \mathrm{~m}^{-2}$ in the wavelength range 290-800 $\mathrm{nm}$. During the experiments, samples were contained in 2-mL Pyrex vials with no headspace and exposed to light while in a water bath maintained at $25{ }^{\circ} \mathrm{C}$. The radiation source was positioned over the vials at a distance of $15 \mathrm{~cm}$; the irradiated path length inside the vials was $10 \mathrm{~mm}$. The experiments were performed in duplicates.

\section{UVC and $\mathrm{UVC} / \mathrm{H}_{2} \mathrm{O}_{2}$ experiments}

The experimental apparatus has been depicted elsewhere (Graça et al. 2017). For photolysis experiments, $100 \mathrm{~mL}$ of an aqueous solution containing $50 \mathrm{mg} \mathrm{L}^{-1}$ of LTX was irradiated in a $2000-\mathrm{mL}$ quartz beaker $(\varnothing$ beaker $=12 \mathrm{~cm}$; solution depth $\sim 1 \mathrm{~cm}$ ), provided with magnetic stirring and thermostatized at $20 \pm 4{ }^{\circ} \mathrm{C}$ by means of a cool water bath. The LTX solution was irradiated by four 8-W lamps (Philips, TUV) emitting $2.53 \mathrm{~W} \mathrm{~m}^{-2}$ UVC radiation at $254 \mathrm{~nm}$; the lamps were positioned over the beaker at a distance of $27 \mathrm{~cm}$ from the liquid surface. The experimental procedure was similar for the $\mathrm{UVC} / \mathrm{H}_{2} \mathrm{O}_{2}$ experiments: $100 \mathrm{~mL}$ of an aqueous solution containing $50 \mathrm{mg} \mathrm{L}^{-1}$ of LTX was irradiated, with $\mathrm{H}_{2} \mathrm{O}_{2}$ added at time zero, at the stoichiometric amount $(0.2 \mathrm{mmol})$ required to mineralize LTX. Solution $\mathrm{pH}$ level was adjusted to the initial desired value $(\sim 6.5)$ but not corrected over reaction time. Samples were collected at every $30 \mathrm{~min}$ of reaction until reaching 120 min of irradiation and mixed with methanol to scavenge the most reactive radicals and stop LTX degradation. All the experiments were performed in duplicates.

\section{Kinetic study: hydroxyl radical and singlet oxygen}

The second-order reaction rate constants between LTX and ROS ( $\mathrm{CH}$ or ${ }^{1} \mathrm{O}_{2}$ ) were determined using the kinetic competition method described by Shemer et al. (2006). According to this method, the pollutant (LTX) competes for ROS in a mixture, with a reference compound (pCBA or FFA, respectively), whose reactivity toward the ROS is known. Hydrogen peroxide and methylene blue were used as the sources of ${ }^{\circ} \mathrm{OH}$ radicals and ${ }^{1} \mathrm{O}_{2}$, respectively, to determine the values of the second-order reaction rate constants between LTX and ${ }^{\circ} \mathrm{OH}\left(k_{\mathrm{LTX}},{ }^{\circ} \mathrm{OH}\right)$ and between LTX and ${ }^{1} \mathrm{O}_{2},\left(k_{\mathrm{LTX}}, 1 \mathrm{O} 2\right)$, respectively. The optimized concentrations used were $12.5 \mu \mathrm{mol} \mathrm{L}^{-1}$ (LTX); $64.1 \mu \mathrm{mol} \mathrm{L}^{-1}$ (pCBA); $102.0 \mu \mathrm{mol} \mathrm{L}^{-1}$ (FFA); $880 \mu \mathrm{mol} \mathrm{L}{ }^{-1}\left(\mathrm{H}_{2} \mathrm{O}_{2}\right)$; and $31 \mu \mathrm{mol} \mathrm{L}{ }^{-1}$ (methylene blue). Samples were quenched with bovine catalase to decompose residual $\mathrm{H}_{2} \mathrm{O}_{2}$ when needed. All competition kinetic experiments were performed in duplicates.

\section{Toxicity assays}

Acute toxicity assays were performed with the crustacean Daphnia similis, in triplicate. Immobility of $D$. similis after $24 \mathrm{~h}$ was the end point measured for this assay. Daphnids were cultivated in laboratory, and the organisms were exposed for $24 \mathrm{~h}$ to (i) non-irradiated $50 \mathrm{mg} \mathrm{L}^{-1}$ LTX solutions and (ii) $50 \mathrm{mg} \mathrm{L}^{-1}$ LTX solutions exposed to UVC radiation for $120 \mathrm{~min}$.

\section{Analytical methods}

Dissolved organic carbon (DOC) was measured using a TOCVSCH (Shimadzu Corp.) analyzer. The method detection limit was $0.2 \mathrm{mg} \mathrm{C} \mathrm{L}^{-1}$.

An HPLC system (Shimadzu), equipped with a twosolvent delivery pump, a UV/VIS diode array detector (SPD 20A model), and an auto sampler, was used to follow LTX, pCBA, and FFA concentration-time profiles. In all the cases, the oven temperature, the sample injection volume, and the mobile phase flow rate were $40{ }^{\circ} \mathrm{C}, 50.0 \mu \mathrm{L}$, and 1.0 $\mathrm{mL} \min ^{-1}$, respectively.

LTX was monitored at $254 \mathrm{~nm}$ using a RP18 column (Waters Spherisorb Phenyl, $250 \mathrm{~mm} \times 4.6 \mathrm{~mm} ; 5 \mu \mathrm{m}$ ); the isocratic elution consisted of (a) $\mathrm{H}_{2} \mathrm{O}+0.2 \%$ formic acid and (b) acetonitrile $+0.2 \%$ formic acid, at 20:80 ratio $(v / v)$. The limits of detection (LOD) and quantification (LOQ) were 0.125 and $0.380 \mathrm{mg} \mathrm{L}^{-1}$, respectively. The chromatograms of LTX solutions sampled at times 0,30 , and 120 min during the $\mathrm{UVC}$ and $\mathrm{UVC} / \mathrm{H}_{2} \mathrm{O}_{2}$ experiments are provided in the Online Resource (Figures S1 and S2).

For FFA and pCBA, a C18 column $(250 \mathrm{~mm} \times 4.6 \mathrm{~mm}$ inner diameter, $5 \mu \mathrm{m}$ ) was used. The isocratic elution with $70 \%$ acetic acid (1\%)/30\% methanol was used to monitor FFA at $219 \mathrm{~nm}$. pCBA was monitored at $234 \mathrm{~nm}$, using 50\% acetic acid $(1 \%) / 55 \%$ methanol as the mobile phase. The LOD and LOQ values were 20.2 and $61.1 \mu \mathrm{g} \mathrm{L}^{-1}$ (FFA), and 4.2 and $12.6 \mu \mathrm{g} \mathrm{L}^{-1}$ (pCBA), respectively.

The investigation of LTX degradation products was performed by mass spectrometric analysis using an UltrafleXtreme MALDI-TOF mass spectrometer (Bruker Daltonics) operating in reflector positive ion mode. Mass 
spectra were acquired in a mass range from 300 to $1500 \mathrm{Da}$ with ions generated from Smartbeam ${ }^{\mathrm{TM}}$ laser irradiation using a frequency of $2000 \mathrm{~Hz}$, a PIE of $100 \mathrm{~ns}$, and a lens voltage of $7 \mathrm{kV}$. The voltage was $25 \mathrm{kV}$ for the first ion source and $23 \mathrm{kV}$ for the second. Each spectrum was generated by averaging 10,000 laser shots, and the laser irradiance was set to 95$100 \%$. Ion gating was set to $1000 \mathrm{Da}$ to exclude ions below this value, including matrix aggregates and other contaminants.

\section{Photochemical simulations}

The photochemical environmental fate of LTX was simulated using the mathematical model developed at the Department of Chemistry of the University of Torino and implemented in the APEX (Aqueous Photochemistry of Environmentally occurring Xenobiotics) software (Laurentiis et al. 2013; Bodrato and Vione 2014). This model has been validated for different pollutants (Vione et al. 2011; Marchetti et al. 2013). Further details and free download of APEX are given at http:// chimica.campusnet.unito.it/do/didattica.pl/Show?_id=4pyh.

Briefly, the photochemical model considers direct photolysis and reactions with ROS. The ${ }^{\circ} \mathrm{OH}$ radical generation results from light absorption by nitrate, nitrite, and chromophoric dissolved organic matter (CDOM), while ${ }^{1} \mathrm{O}_{2}$ generation is a result of CDOM irradiation, as shown in Eqs. 1, 2, 3, and 4.

$$
\begin{aligned}
& \mathrm{NO}_{3}{ }^{-}+h v+\mathrm{H}^{+} \rightarrow{ }^{\circ} \mathrm{OH}+\mathrm{NO}_{2}{ }^{\cdot} \\
& \mathrm{NO}_{2}{ }^{-}+h v+\mathrm{H}^{+} \rightarrow{ }^{\circ} \mathrm{OH}+\mathrm{NO}^{\cdot} \\
& \mathrm{CDOM}^{*} h v \rightarrow{ }^{1} \mathrm{CDOM}^{*} \rightarrow{ }^{3} \mathrm{CDOM}^{*} \\
& { }^{3} \mathrm{CDOM}^{*}+\mathrm{O}_{2} \rightarrow \mathrm{CDOM}+{ }^{1} \mathrm{O}_{2}
\end{aligned}
$$

Reactions involving scavengers $\left(\mathrm{HCO}_{3}{ }^{-}, \mathrm{CO}_{3}{ }^{2-}, \mathrm{NO}_{2}{ }^{-}\right)$ are also considered in the APEX model, as given by Eqs. 5, 6 and 7 :

$$
\begin{aligned}
& \cdot \mathrm{OH}+\mathrm{HCO}_{3}{ }^{-} \rightarrow \mathrm{H}_{2} \mathrm{O}+\mathrm{CO}_{3}{ }^{-} \\
& \cdot \mathrm{OH}+\mathrm{CO}_{3}{ }^{2-} \rightarrow \mathrm{OH}^{-}+\mathrm{CO}_{3}{ }^{\cdot-} \\
& \cdot \mathrm{OH}+\mathrm{NO}_{2}{ }^{-} \rightarrow \mathrm{OH}^{-}+\mathrm{NO}_{2}{ }_{2}
\end{aligned}
$$

The model considers the reactions of ${ }^{\circ} \mathrm{OH}$ radicals with dissolved organic matter (DOM), bicarbonate, carbonate, and nitrite and deactivation of ${ }^{1} \mathrm{O}_{2}$ by collisions with solvent molecules (Bodrato and Vione 2014). It is worth observing that bicarbonate and carbonate concentrations do not vary independently due to the acid-base equilibrium involved. As a consequence, the composition of the $\mathrm{HCO}_{3}{ }^{-} / \mathrm{CO}_{3}{ }^{2-}$ system in water strongly depends on $\mathrm{pH}$ level (Oppenlander 2003). In the present work, the APEX model was therefore modified accordingly, as described in a previous publication (Silva et al. 2015).
The degradation kinetics of a given pollutant $P$ by the reactive oxygen species $j$ (here ${ }^{\circ} \mathrm{OH}$ or ${ }^{1} \mathrm{O}_{2}$ ) is expressed in the APEX model as the sum of the second-order rate constant of the reaction between $P$ and $j\left(k_{P, j}\right)$ multiplied by $j$ concentration:

$k_{P, j}^{\prime}=\sum k_{P, j}[j]$

The rate of direct photolysis of a pollutant $P\left(r_{P}\right)$ in the APEX model is given by:

$r_{P}=\int \Phi_{\text {direct phot }}(\lambda) \frac{A P(\lambda)}{A_{\text {tot }}(\lambda)} p^{0}(\lambda)\left(1-10^{-A_{\text {tot }}(\lambda)}\right) d(\lambda)$

where $\Phi_{\text {direct phot }}$ is the photolysis quantum yield; $A_{P}(\lambda)$ is the absorbance of $P$ at $\lambda ; A_{\text {tot }}(\lambda)$ is the total absorbance of the reaction medium; and $p^{0}(\lambda)$ refers to the incident spectral sunlight photon flux density. The pseudo first-order rate constant of the direct photolysis is expressed as follows:

$k_{P, \text { direct phot }}=\frac{r_{P}}{[P]}$

Finally, the APEX model considers the pseudo first-order rate of $P$ degradation as the sum of the contributions of direct and indirect photolysis, and from this constant, the pollutant half-life time is calculated as shown in Eq. 12.

$k_{P}=k_{P, j}^{\prime}+k_{P, \text { direct phot }}$

$t_{1 / 2}=\frac{\ln 2}{k_{P}}$

The required input data are the photolysis quantum yield of the pollutant under sunlight and the second-order rate constants of its reaction with ROS, which were experimentally measured in the present work and are reported here for the first time. Also, typical values of the nitrate, nitrite, and bicarbonate concentrations, as well as $\mathrm{pH}$, were selected from a literature review for Brazilian rivers (Silva et al. 2015).

\section{Results and discussion}

\section{Molar absorption coefficient}

Figure 2 shows that the overlap between the absorption spectrum of LTX in aqueous solution and the emission spectrum of the solar simulator, a necessary condition for the direct photolysis of the pollutant, is satisfied.

The direct photolysis of LTX was very slow under solar irradiation in ultrapure water, as indicated by the linear time behavior of $\ln \left([\mathrm{LTX}] /[\mathrm{LTX}]_{0}\right.$ ) (Fig. 3).

The experimental first-order-specific LTX photolysis rate $\left(k_{P \text {, direct phot }}\right)$ was used with the pollutant molar absorption coefficient to calculate the direct photolysis quantum yield 
Fig. 2 Absorption spectrum of sodium levothyroxine (LTX) in aqueous solution (straight line) and spectral irradiance of the solar simulator (dashed line)

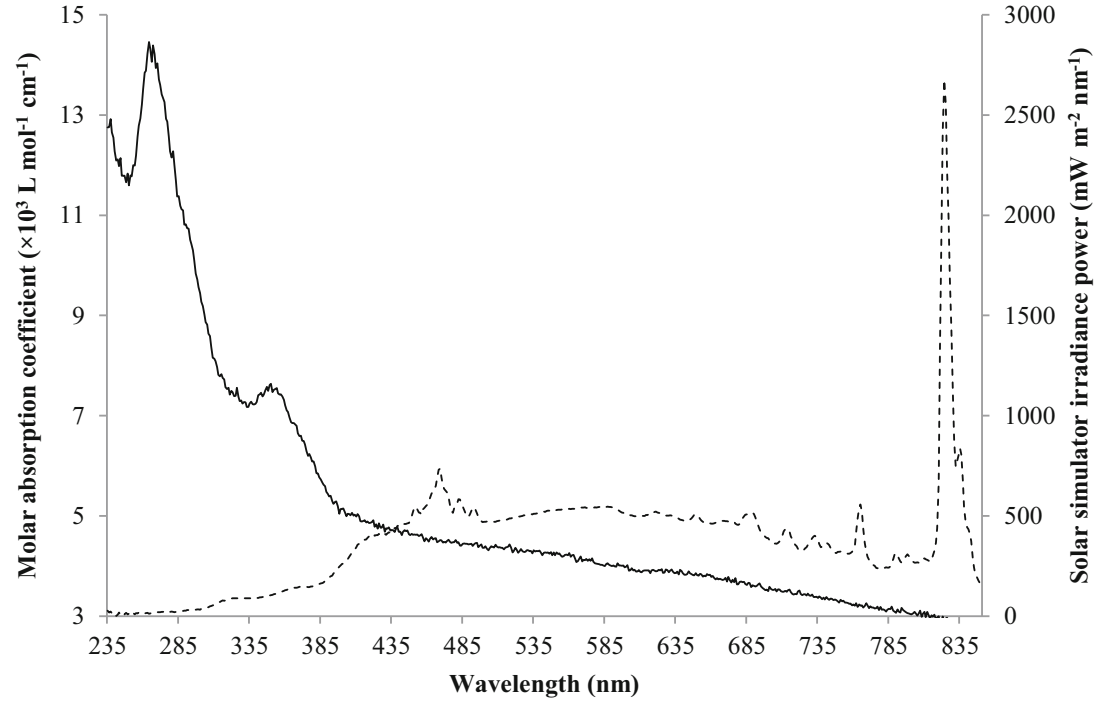

\section{Second-order rate constants of the reactions between LTX and reactive oxygen species}

The second-order kinetic rate constants of LTX with ${ }^{\circ} \mathrm{OH}$ $\left(k_{\mathrm{LTX}, \cdot \mathrm{OH}}\right)$ and ${ }^{1} \mathrm{O}_{2}\left(k_{\mathrm{LTX}, 1 \mathrm{O} 2}\right)$ were determined by using methylene blue and $\mathrm{H}_{2} \mathrm{O}_{2}$ as the ROS sources, respectively. The competition kinetics method between LTX and pCBA for ${ }^{\circ} \mathrm{OH}$, and between LTX and FFA for ${ }^{1} \mathrm{O}_{2}$, was employed. The values of $k_{\mathrm{LTX}, \mathrm{OH}}$ and $k_{\mathrm{LTX}, 1 \mathrm{O} 2}$ were determined using Eq. 18:

$k_{\mathrm{LTX}, \mathrm{ROS}}=\frac{\left(k_{L T X(o b s)}-k_{L T X, \text { direct phot }}\right)}{\left(k_{\text {ref }(\text { obs })}-k_{\text {ref,direct phot }}\right)} \times k_{\mathrm{ref}, \mathrm{ROS}}$

where $\operatorname{ka}(\lambda)$ corresponds to the specific rate of light absorption by LTX and expresses the number (moles) of photons of wavelength $\lambda$ that are absorbed per unit time per mole of LTX present in the system; $W(\lambda)$ is the spectral photon fluence rate (Einstein $\mathrm{cm}^{-2} \mathrm{~s}^{-1} \mathrm{~nm}^{-1}$ ) of the simulated solar light; $\alpha(\lambda)$ is the decadic attenuation coefficient of the medium $\left(\mathrm{cm}^{-1}\right)$ and $z$ is the irradiated liquid depth $(10 \mathrm{~mm})$. The LTX direct photolysis quantum yield $\left(\Phi_{\text {LTX }}\right)$ under sunlight was therefore estimated as $\Phi_{\mathrm{LTX}}=3.80( \pm 0.02) \times 10^{-5}$, a very low value. where $k$ LTX,ROS is the rate constant of the reaction between LTX and the reactive oxygen species (ROS), ${ }^{1} \mathrm{O}_{2}$ or 'OH; $k$ LTX(obs) is the measured pseudo first-order degradation rate constant of sodium levothyroxine for each ROS; $k$ ref(obs) is the measured pseudo first-order
Fig. 3 LTX direct photolysis under simulated solar light

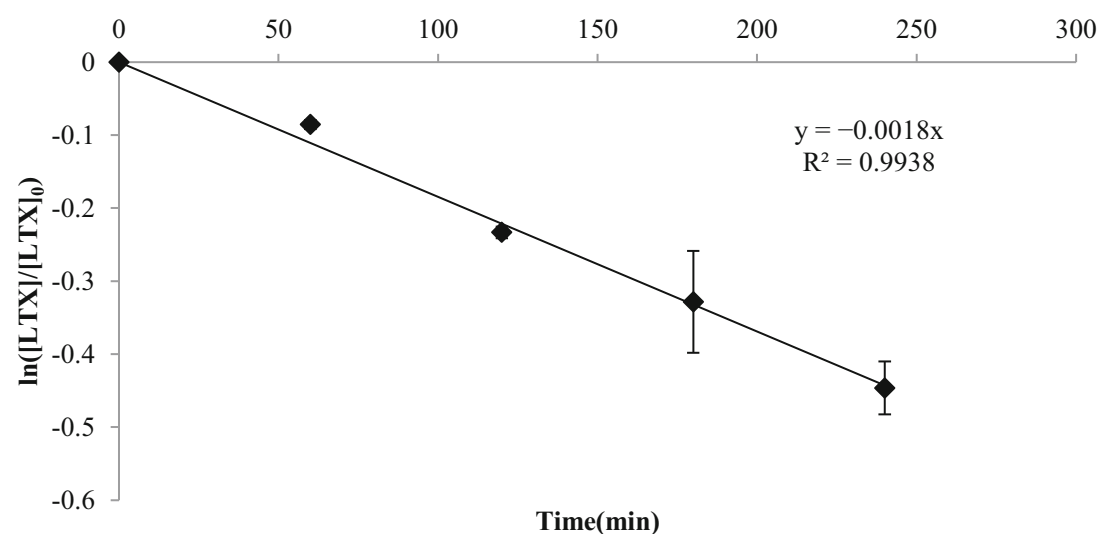


degradation rate constant of the reference compound (FFA or pCBA); $k_{\text {LTX, direct phot }}$ and $k_{\text {ref, direct phot }}$ are the measured direct photolysis rate constants for LTX and the reference compound, respectively; $k$ ref, ROS is the second-order rate constant of the reaction between the reference compound and ROS, $k \mathrm{FFA},{ }_{1 \mathrm{O} 2}=1.2 \times 10^{8}$ $\mathrm{L} \mathrm{mol}^{-1} \mathrm{~s}^{-1}$ (Mostafa and Rosario-Ortiz 2013) and $k \mathrm{pCBA}, \cdot \mathrm{OH}=5 \times 10^{9} \mathrm{~L} \mathrm{~mol}^{-1} \mathrm{~s}^{-1}$ (Elovitz and von Gunten 1999). Figure 4 shows the apparent first-order behavior of LTX concentrations and the reference compounds over time, according to the competition kinetics experiments.

From these results, the measured values of $k_{\mathrm{LTX}} \cdot \mathrm{OH}$ and $k_{\mathrm{LTX}, 1 \mathrm{O} 2}$ were $(1.50 \pm 0.01) \times 10^{10} \mathrm{~L} \mathrm{~mol}^{-1} \mathrm{~s}^{-1}$ and $(1.47 \pm$ $0.66) \times 10^{8} \mathrm{~L} \mathrm{~mol}^{-1} \mathrm{~s}^{-1}$, respectively, suggesting that the attack of LTX molecules by hydroxyl radicals is the dominant mechanism during hormone degradation in surface waters exposed to sunlight. Duan et al. (2017) determined $k_{\mathrm{LTX}, \cdot \mathrm{OH}}$ and found a same order value, $(1.01 \pm 0.02) \times 10^{10} \mathrm{~L} \mathrm{~mol}^{-1} \mathrm{~s}^{-1}$.

\section{Photochemical simulations}

The LTX half-life time $\left(t_{1 / 2}\right)$ was simulated as a function of environmental variables, such as water characteristics and column depth, by means of the software APEX, considering the experimental values of $\Phi_{\mathrm{LTX}}, k_{\mathrm{LTX}, \cdot \mathrm{OH}}$, and $k_{\mathrm{LTX}, 1 \mathrm{O} 2}$.

The ranges of values of the model variables (nitrate, nitrite, bicarbonate, and dissolved organic matter concentrations) were selected based on a previous publication (Silva et al. 2015), which presents an extensive review of published data on Brazilian rivers (see Online Resource, Table S1). In the simulations discussed therein, the column water depth was varied between 0.5 and $5 \mathrm{~m}$, and the $\mathrm{pH}$ level between 6.5 and 9.5. The APEX simulations were organized according to a factorial design at two levels of each variable $\left(2^{6}\right)$ (Box et al. 1978) (see Online Resource, Table S2).

The variables that showed greater importance to LTX degradation were water depth, DOC concentration, and nitrite concentration. The predicted LTX degradation as a function
Fig. 4 Results of the competition kinetics experiments. a Data for the determination of $k_{\mathrm{LTX}, \cdot \mathrm{OH}}$ : black diamond indicates observed pCBA degradation; black square indicates observed LTX degradation; and black circle indicates LTX direct photolysis. $\mathbf{b}$ Data for the determination of $k_{\mathrm{LTX}, 1 \mathrm{O} 2}$ : white diamond indicates observed FFA degradation; white square indicates observed LTX degradation; and white circle indicates LTX direct photolysis. In the vertical axis titles, [compound] refers to [LTX], [pCBA], or [FFA]

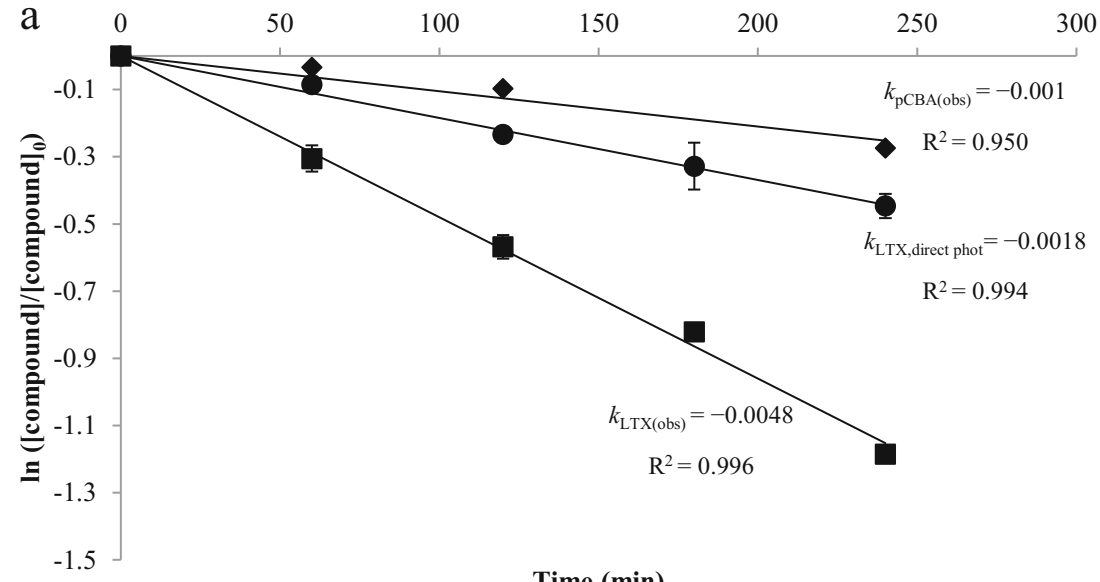

Time (min)

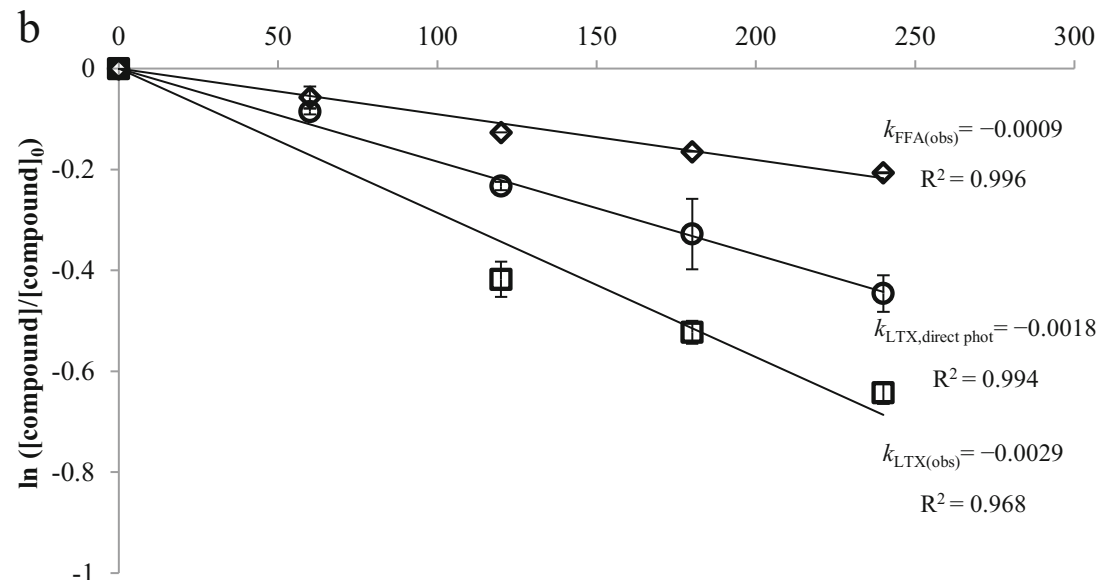

Time (min) 
of water column depth and DOC concentration is shown in Fig. 5, which indicates that $t_{1 / 2}$ varies from less than 10 days (for $0.5-\mathrm{m}$ depth and $\mathrm{DOC}=0.5 \mathrm{mg} \mathrm{L}^{-1}$ ) to more than 3 months (for 5-m depth and DOC $=10 \mathrm{mg} \mathrm{L}^{-1}$ ).

Figure 5 also shows that a 10 -fold increase in depth at low DOC levels contributes only to a slight increase of about 2.3 days in $t_{1 / 2}$. In contrast, for the same increase in depth, a 4-fold increase in LTX half-life is expected at higher DOC concentrations. The increase in half-life time with depth at higher DOC concentrations was also observed for the herbicides cycloxydim (Vione 2014), amicarbazone (Silva et al. 2015), diuron, fenuron, isoproturon, metoxuron, and chlortoluron (Fabbri et al. 2015) and for the antimicrobial agent triclosan (Bianco et al. 2015).

As expected, poorly sunlit, deep-water bodies contribute to an increase in LTX persistence. In contrast, the higher persistence of pollutants in DOC-rich water bodies depends on several factors. Higher DOC concentrations mean higher DOM and CDOM contents; while CDOM is a photochemical source of hydroxyl radicals, DOM often acts as an important ${ }^{\circ} \mathrm{OH}$ scavenger (Passananti et al. 2014). CDOM also strongly absorbs and competes with pollutants for sunlight, slowing down the direct photolysis of the pollutant (Vione 2014).

The predicted effects of nitrite and DOC concentrations on LTX half-life time, according to the APEX model calculations, are shown in Fig. 6. Nitrite is a source and a sink of 'OH radicals, as shown by Eqs. 2 and 7, respectively. However, a more pronounced influence of this species as a source of ${ }^{\circ} \mathrm{OH}$ radicals is suggested in the conditions studied, since a 300-fold increase in nitrite concentration results in a decrease in LTX half-life time of 1.8 times on average, as shown in Figs. 6 and 7.

Finally, Fig. 7 shows the predicted effect of water depth and nitrite concentration on LTX persistence in water bodies, indicating a more pronounced effect of water depth in comparison with nitrite regarding LTX persistence.

\section{LTX removal by UVC and the advanced oxidation process $\mathrm{UVC} / \mathrm{H}_{2} \mathrm{O}_{2}$}

The long environmental LTX half-life time (almost 80 days) predicted by mathematical simulations, along with its recalcitrance and inefficient degradation by conventional treatment process (Dong et al. 2013), points out the need of suitable treatment methods for remediating LTX-containing wastewaters to prevent contamination of natural aqueous systems and/ or to treat water impacted by LTX for drinking water supply purposes. It is worth observing that investigations aimed at studying LTX removal from wastewaters before their discharge are scarce in the literature. Therefore, the UVC- and $\mathrm{UVC} / \mathrm{H}_{2} \mathrm{O}_{2}$-driven LTX degradation at $254 \mathrm{~nm}$ was investigated in this work; the results are shown in Fig. 8.

LTX removal by both processes followed pseudo firstorder decay, achieving $85 \%$ degradation after $120 \mathrm{~min}$ by UVC photolysis at $254 \mathrm{~nm}$. A considerable improvement in LTX removal was obtained with the addition of $\mathrm{H}_{2} \mathrm{O}_{2}$, with 95\% removal after $120 \mathrm{~min}$ of irradiation. These results are associated with the high absorption of LTX at $254 \mathrm{~nm}(\varepsilon=$
Fig. 5 Effect of water depth and DOC concentration on LTX halflife as predicted by the APEX model. All the other variables were fixed at their average values: $\left[\mathrm{NO}_{3}{ }^{-}\right]=50.5 \mu \mathrm{mol} \mathrm{L}{ }^{-1}$, $\left[\mathrm{HCO}_{3}{ }^{-}\right]=1.1 \times 10^{3} \mu \mathrm{mol} \mathrm{L}^{-1}$, and $\left[\mathrm{NO}_{2}^{-}\right]=7.5 \mu \mathrm{mol} \mathrm{L}^{-1}$

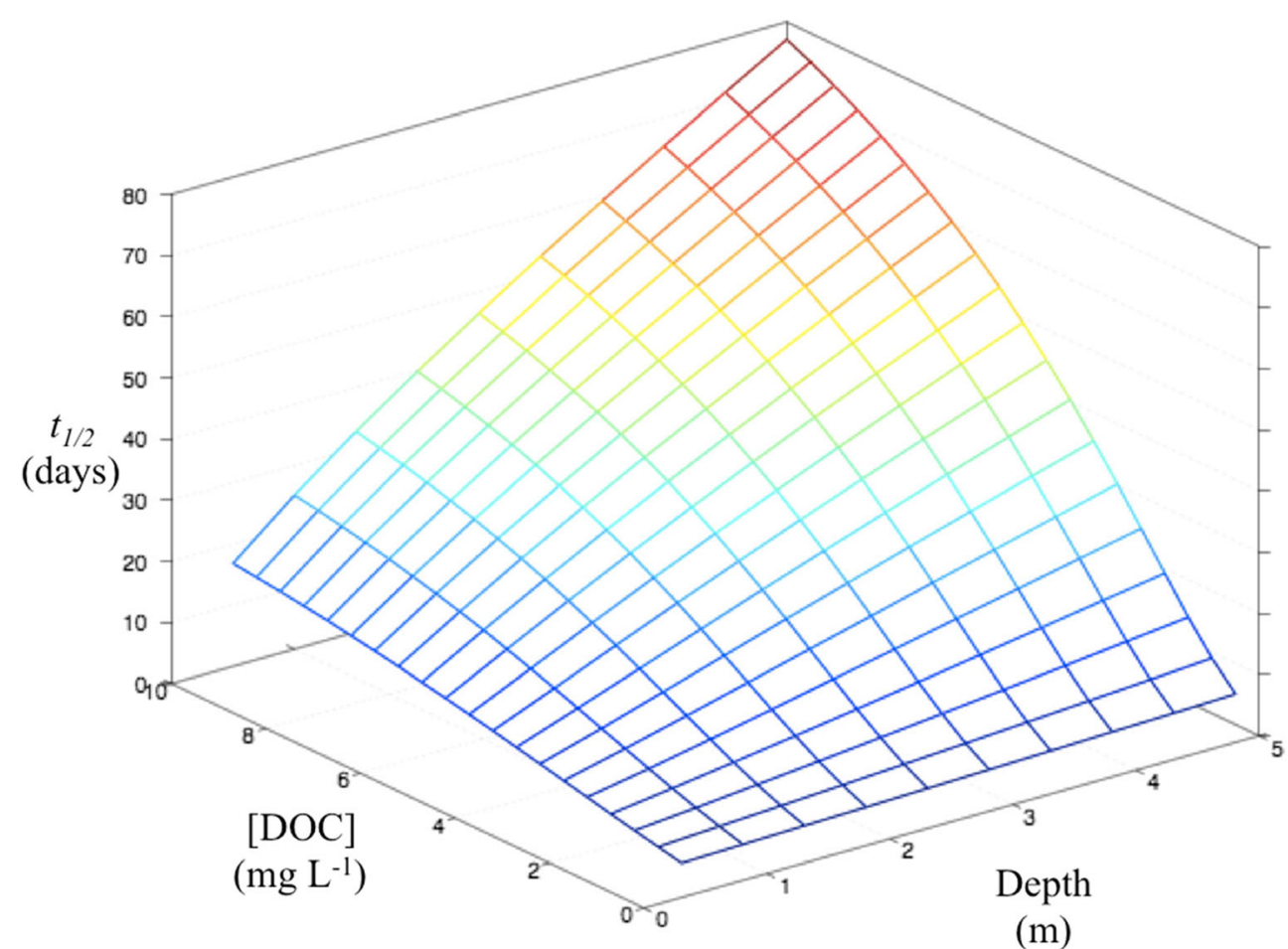


Fig. 6 Effect of nitrite and DOC concentrations on LTX half-life as predicted by the APEX model. All the other variables were fixed at their average values: $\left[\mathrm{NO}_{3}{ }^{-}\right]=$ $50.5 \mu \mathrm{mol} \mathrm{L}^{-1},\left[\mathrm{HCO}_{3}{ }^{-}\right]=1.1 \times$ $10^{3} \mu \mathrm{mol} \mathrm{L}{ }^{-1}$, and 2.75-m water depth

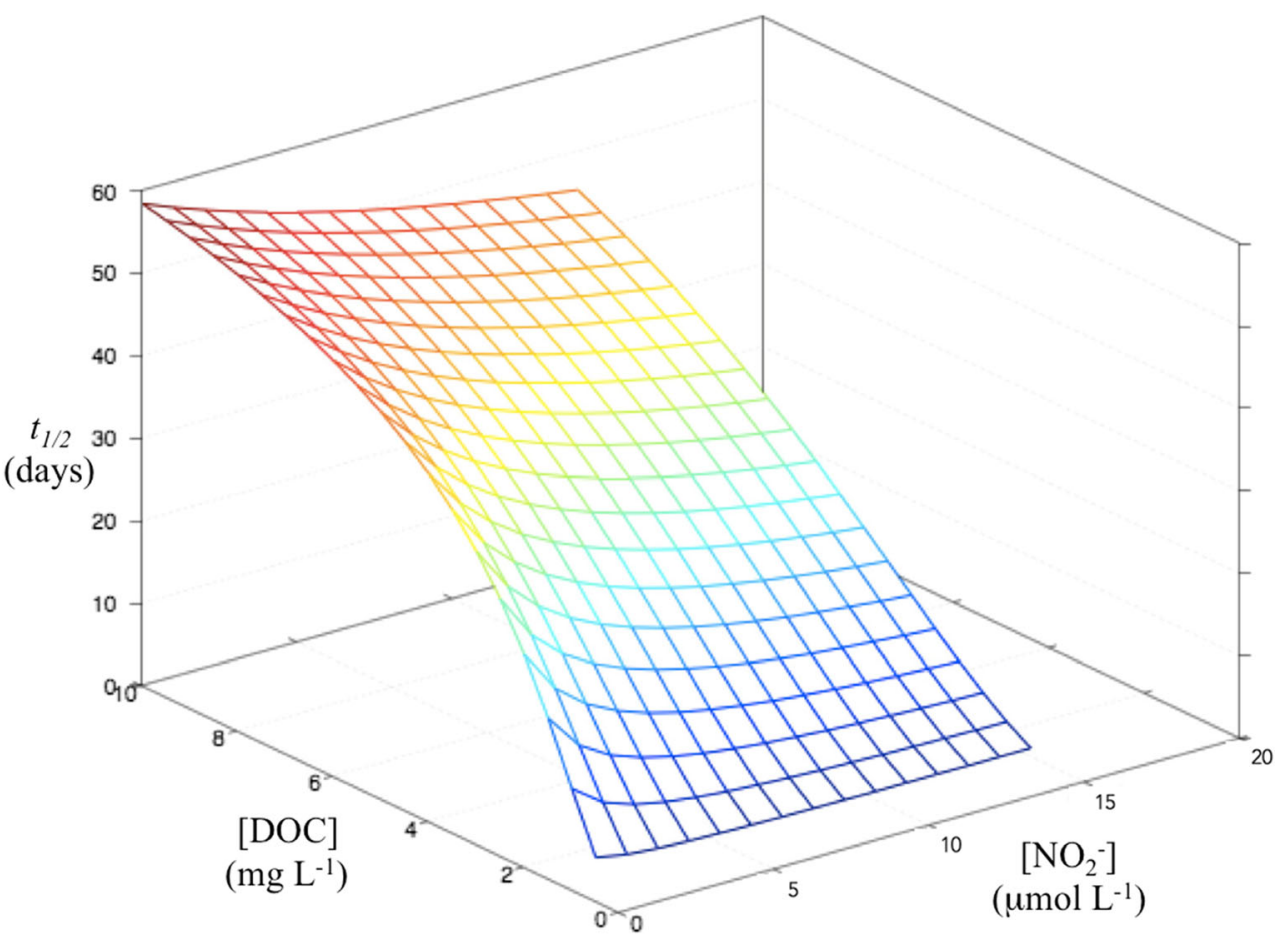

$1.08 \times 10^{4} \mathrm{~L} \mathrm{~mol}^{-1} \mathrm{~cm}^{-1}$, Fig. 2) and the large value of $k_{\text {LTX. }} \cdot$ OH. Duan et al. (2017) investigated UVC and UVC/ $\mathrm{H}_{2} \mathrm{O}_{2}$ applied to LTX degradation. The authors also observed increased degradation efficiency by $\mathrm{UVC} / \mathrm{H}_{2} \mathrm{O}_{2}$ compared with UVC, a removal of approximately $40 \%$ of $0.5 \mu \mathrm{mol} \mathrm{L}^{-1}$ LTX after $160 \mathrm{~min}$ through direct photolysis at
UV fluence of $160 \mathrm{~mJ} \mathrm{~cm}{ }^{-2}$ and $60 \%$ with $\mathrm{H}_{2} \mathrm{O}_{2}$ addition were obtained.

Despite the very good results achieved by the UVC and $\mathrm{UVC} / \mathrm{H}_{2} \mathrm{O}_{2}$ processes regarding LTX degradation, TOC analyses showed virtually no mineralization, which is associated with the formation of persistent degradation products.
Fig. 7 Effect of water depth and nitrite concentration on LTX halflife as predicted by the APEX model. All the other variables were fixed at their average values: $\left[\mathrm{NO}_{3}{ }^{-}\right]=50.5 \mu \mathrm{mol} \mathrm{L}{ }^{-1}$, $\left[\mathrm{HCO}_{3}{ }^{-}\right]=1.1 \times 10^{3} \mu \mathrm{mol} \mathrm{L}^{-1}$, and $[\mathrm{DOC}]=5.25 \mathrm{mg} \mathrm{L}^{-1}$

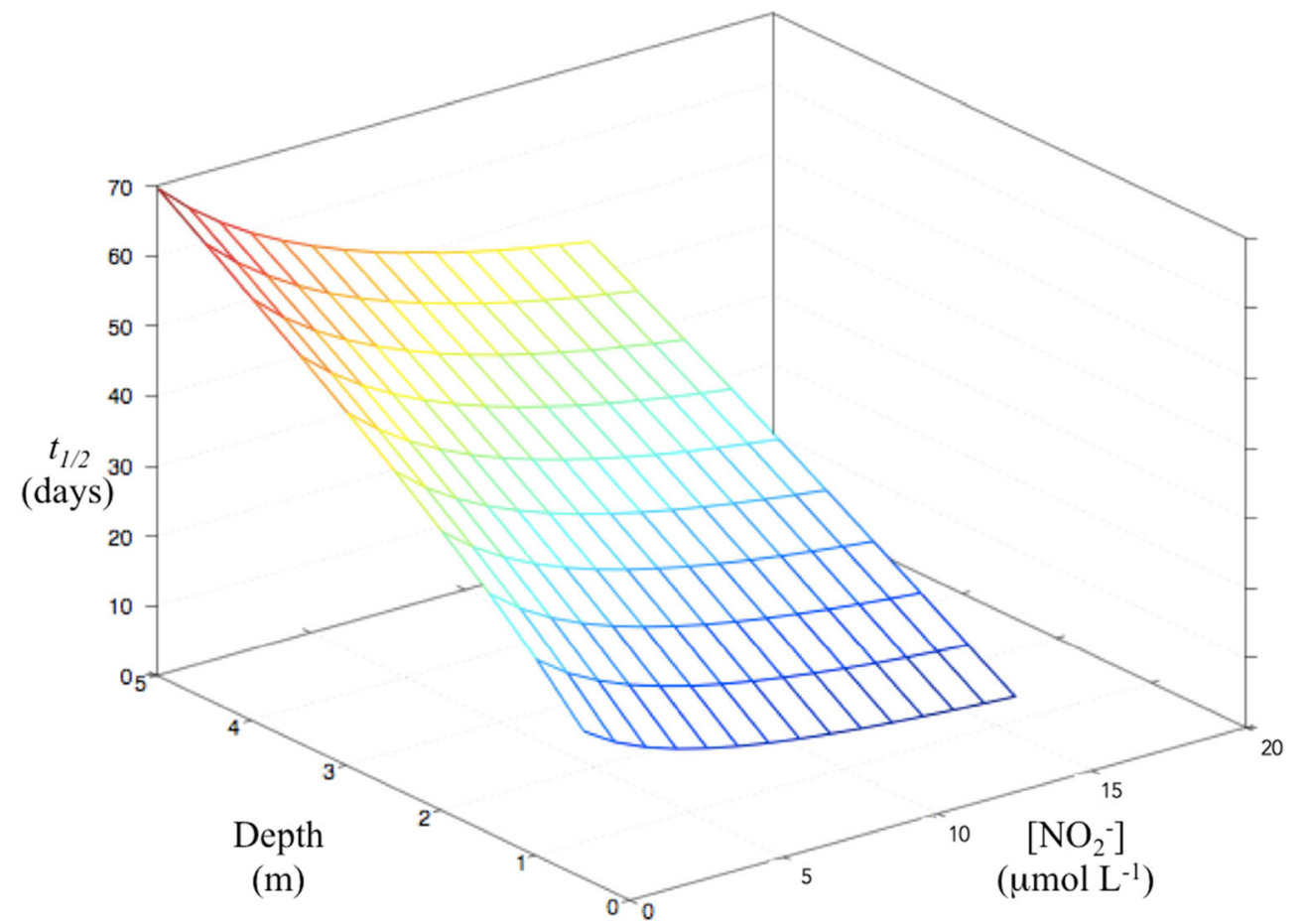


Fig. 8 LTX degradation by UVC photo-irradiated processes $\left([\mathrm{LTX}]_{0}=50 \mathrm{mg} \mathrm{L}^{-1}\right.$ and $\mathrm{pH}_{0}$ 6.5). a - UVC photolysis at $254 \mathrm{~nm}$. b $-\bullet-\mathrm{UVC} / \mathrm{H}_{2} \mathrm{O}_{2}$ process

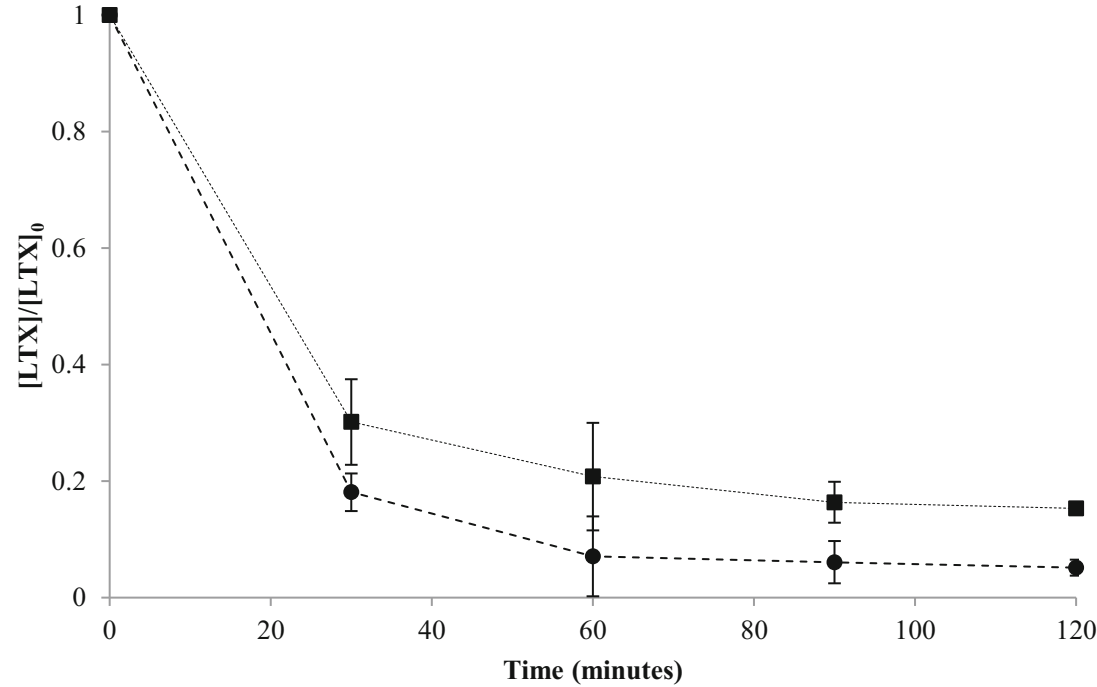

Toxicity measurements showed that untreated samples immobilized $52.4 \%$ of exposed living organisms (D. similis) after $24 \mathrm{~h}$, while $100 \%$ of exposed living organisms were immobilized after $24 \mathrm{~h}$ in LTX-irradiated solutions. These results suggest that the transformation products present in UVC-treated LTX solutions, which are associated with the remaining TOC, increased the acute toxicity to $D$. similis. Further investigation is required to correlate degradation byproducts with the toxicity bioassay results.

\section{LTX photodegradation byproducts}

Besides the LTX persistence predicted by the simulations, which is almost 80 days depending on water characteristics, photodegradation products will be also present in surface waters contaminated by LTX. Nevertheless, there are few published studies devoted to identifying LTX degradation products under sunlight.
Van der Walt and Cahnmann (1982) reported that thyroxine under irradiation above $300 \mathrm{~nm}$ leads to stepwise removal of iodine atoms, those in the phenolic ring being removed preferentially. They showed the release of iodine atoms from the phenolic ring with formation of triiodothyronine and diiodothyronine following thyroxine irradiation above $340 \mathrm{~nm}$. Kazemifard et al. (2001) identified degradation products formed upon LTX irradiation by a 320-nm monochromatic source. The immediate degradation product formed was identified as liothyronine, the major LTX end product found was tyrosine, and also small amounts of diiodothyronine, iodothyronine, diiodotyrosine, and iodotyrosine were identified (Kazemifard et al. 2001). More recently, Svanfelt et al. (2011) identified two major photo-transformation products from LTX photodegradation in the wavelength range 300$400 \mathrm{~nm}$. Elemental composition of the major product formed was $\mathrm{C}_{14} \mathrm{H}_{14} \mathrm{I}_{2} \mathrm{NO}_{5}$, which exhibits insignificant UV absorption and hence was found to be photo-stable (Svanfelt et al. 2011).

Table 1 Chemical structures of the transformation products from LTX degradation by the UVC and $\mathrm{UVC} / \mathrm{H}_{2} \mathrm{O}_{2}$ processes

\begin{tabular}{c|c|c}
\hline $\begin{array}{c}\text { Triiodothyronine } \\
(\mathrm{m} / \mathrm{z}=652)\end{array}$ & $\begin{array}{c}\text { Diiodothyronine } \\
(\mathrm{m} / \mathrm{z}=526)\end{array}$ \\
\hline $\mathrm{C}_{15} \mathrm{H}_{12} \mathrm{I}_{3} \mathrm{NO}_{4}$ & $\mathrm{C}_{15} \mathrm{H}_{13} \mathrm{I}_{2} \mathrm{NO}_{4}$ & $\begin{array}{c}\text { Diiodotyrosine } \\
(\mathrm{m} / \mathrm{z}=434)\end{array}$ \\
\hline
\end{tabular}


The second product detected by therein was identified as diiodotyrosine. According to Svanfelt et al. (2011), diiodotyrosine is formed through the photolytic cleavage of the ether linkage connecting the two phenyl moieties in LTX and it is not photo-stable.

A detailed mass spectrometry study was performed to identify the main products formed from LTX degradation by the UVC and $\mathrm{UVC} / \mathrm{H}_{2} \mathrm{O}_{2}$ processes. The transformation products identified by MALDI-TOF mass spectrometry are depicted in Table 1. In both process cases, the byproducts triiodothyronine $(\mathrm{m} / \mathrm{z}=652)$, diiodothyronine $(\mathrm{m} / \mathrm{z}=526)$, and diiodotyrosine $(\mathrm{m} / \mathrm{z}=434)$ were identified; the same degradation products were observed by Duan et al. (2017) for UVC-based photochemical processes (UVC, UVC/ $\mathrm{H}_{2} \mathrm{O}_{2}$, and $\mathrm{UVC} / \mathrm{S}_{2} \mathrm{O}_{8}{ }^{2-}$ ).

The results suggest that the first step in LTX degradation by UVC-based photochemical processes involves the release of iodine atoms. In fact, Duan et al. (2017) confirmed that the CI bond is photosensitive and readily cleaved, by monitoring the formation of $\Gamma^{-}$anions during UVC-driven LTX degradation. The authors observed that $50 \%$ of $\mathrm{I}^{-}$was released after $270 \mathrm{~min}$ of UVC irradiation. The presence of diiodotyrosine in the irradiated solutions indicates that the release of the whole phenol group is a step of LTX degradation by UVC-based processes.

From these previous investigations and our experimental results, it is possible to conclude that $\mathrm{C}-\mathrm{I}$ bonds are photo labile and readily cleaved; consequently, the first steps of LTX photodegradation involve the release of iodine atoms. Previous studies also suggest that both stable and non-stable photoproducts are formed (Svanfelt et al. 2011).

\section{Conclusion}

Mathematical simulations indicate that LTX half-life times can vary from less than 10 days to about 80 days depending on the range of environmental conditions. LTX photodegradation is favored in shallow, nitrite-rich, and DOM-poor environments. Previous studies suggest that both stable and nonstable photoproducts are formed from LTX degradation under sunlight. These results are of great importance in the assessment of the exposure of aquatic ecosystems and human communities to water contamination by the synthetic hormone LTX.

UVC-based photochemical processes prove to be feasible to remove the synthetic hormone LTX from water, with more than 85 and 95\% LTX removals achieved by UVC photolysis and $\mathrm{UVC} / \mathrm{H}_{2} \mathrm{O}_{2}$ after $120 \mathrm{~min}$, respectively. Complete mineralization was not observed even in the $\mathrm{UVC} / \mathrm{H}_{2} \mathrm{O}_{2}$ process, which is associated with the formation of persistent degradation products.
Three transformation products, triiodothyronine $(\mathrm{m} / \mathrm{z}=$ $652)$, diiodothyronine $(\mathrm{m} / \mathrm{z}=526)$, and diiodotyrosine $(\mathrm{m} /$ $z=434$ ), were identified using mass spectrometry during LTX degradation by the UVC-based photochemical processes studied. The bioassay with Daphnia similis suggests that UVC irradiation was not efficient for removing toxicity from LTXcontaining water and in fact, UVC-treated solutions were shown to be more toxic to $D$. similis than untreated samples.

The knowledge of photo-induced kinetics coupled with environmental fate simulations may help evaluate the persistence of recalcitrant pollutants such as LTX, and also indicate the need for specific treatments for public water supply.

Funding information The authors thank the Coordination for the Improvement of Higher Education Personnel (CAPES) and the São Paulo Research Foundation (FAPESP, grant \#2013/50218-2) for the financial support.

\section{Compliance with ethical standards}

Conflict of interest The authors declare that they have no competing interests.

\section{References}

Abdallah S, Mohamed I (2016) Factor affecting photo and thermal stability of levothyroxine sodium. Br J Pharm Res 10:1-11. https://doi. org/10.9734/BJPR/2016/23410

ANVISA (2017) Brazilian health regulatory agency. Statistical Book of Pharmaceutical Market, Brazil

Bila DM, Dezotti M (2003) Fármacos no meio ambiente. Quim Nova 26: 523-530. https://doi.org/10.1590/S0100-40422003000400015

Bianco A, Fabbri D, Minella M, Brigante M, Mailhot G, Maurino V, Minero C, Vione D (2015) New insights into the environmental photochemistry of 5-chloro-2-(2,4- dichlorophenoxy)phenol (triclosan): reconsidering the importance of indirect photoreactions. Water Res 72:271-280. https://doi.org/10.1016/j.watres.2014.07.036

Bodrato M, Vione D (2014) APEX (Aqueous Photochemistry of Environmentally occurring Xenobiotics): a free software tool to predict the kinetics of photochemical processes in surface waters. Environ Sci Process Impacts 16:732-740. https://doi.org/10.1039/ c3em00541k

Bolk N, Visser TJ, Nijman J, Jongste I, Tijssen JGP, Berghout A (2010) Effects of evening vs morning levothyroxine intake. Arch Intern Med 170:1996-2000. https://doi.org/10.1001/archinternmed

Boreen AL, Arnold WA, Mcneill K (2004) Photochemical fate of sulfa drugs in the aquatic environmental: sulfa drugs containing fivemembered heterocyclic groups. Environ Sci Technol 38:39333940. https://doi.org/10.1021/es0353053

Box GEP, Hunter WG, Hunter JS (1978) Statistics for experimenters: an introduction to design, data analysis and model building. Wiley, New York

Cappelli C, Pirola I, Gandossi E, Formenti A, Castellano M (2013) Oral liquid levothyroxine treatment at breakfast: a mistake? Eur J Endocrinol 170:95-99. https://doi.org/10.1530/EJE-13-0693

Dong Z, Senn DB, Moran RE, Shine JP (2013) Prioritizing environmental risk of prescription pharmaceuticals. Regul Toxicol Pharmacol 65:60-67. https://doi.org/10.1016/j.yrtph.2012.07.003

Duan XD, He X, Wang D, Mezyk SP, Otto SC, Marfil-Vega R, Mills MA, Dionysiou DD (2017) Decomposition of iodinated pharmaceuticals 
by UV-254 nm-assisted advanced oxidation processes. J Hazard Mater 323:489-499. https://doi.org/10.1016/j.jhazmat.2016.04.022

Elovitz MS, von Gunten U (1999) Hydroxyl radical ozone ratios during ozonation processes. I-the R-ct concept. Ozone Sci Eng 21:239260. https://doi.org/10.1080/01919519908547239

Fabbri D, Minella M, Maurino V, Minero C, Vione D (2015) Photochemical transformation of phenylurea herbicides in surface waters: a model assessment of persistence, and implications for the possible generation of hazardous intermediates. Chemosphere 19: 601-607. https://doi.org/10.1016/j.chemosphere.2014.07.034

Graça CAL, Correia AV, Teixeira ACSC (2017) Role of Fe(III)-carboxylates in AMZ photodegradation: a response surface study based on a Doehlert experimental design. Chemosphere 184:981-991. https:// doi.org/10.1016/j.chemosphere.2017.06.013

Harris DC (2003) Quantitative chemical analysis, 6th edn. W.H. Freeman and Co., New York

Ianiro G, Mangiola F, Di Rienzo TA, Bibbò S, Franceschi F, Greco AV, Gasbarrini A (2014) Levothyroxine absorption in health and disease, and new therapeutic perspectives. Eur Rev Med Pharmacol Sci 18:451-456

Kazemifard AG, Moore DE, Aghazadeh A (2001) Identification and quantitation of sodium-thyroxine and its degradation products by LC using electrochemical and MS detection. J Pharm Biomed Anal 25:697-711. https://doi.org/10.1016/S0731-7085(01)00370-3

Kostich MS, Lazorchak JM (2008) Risks to aquatic organisms posed by human pharmaceutical use. Sci Total Environ 389:329-339. https:// doi.org/10.1016/j.scitotenv.2007.09.008

Lam MW, Mabury SA (2005) Photodegradation of the pharmaceuticals atorvastatin, carbamazepine, levofloxacin, and sulfamethoxazole in natural waters. Aquat Sci 67:177-188. https://doi.org/10.1007/ s00027-004-0768-8

Laurentiis ED, Chiron S, Kouras-Hadef S, Richard C, Minella M, Maurino V, Minero C, Vione D (2012) Photochemical fate of carbamazepine in surface freshwaters: laboratory measures and modeling. Environ Sci Technol 46:8164-8173. https://doi.org/10.1021/ es3015887

Laurentiis E, Minella M, Brodato M, Maurino V, Minero C, Vione D (2013) Modeling the photochemical generation kinetics of 2-methyl-4-chlorophenol, an intermediate of the herbicide MCPA (2 methyl-4-chlorophenoxyacetic acid) in surface waters. Aquat Ecosyst Health Manag 16:216-221. https://doi.org/10.1080/ 14634988.2013.788433

Marchetti G, Minella M, Maurino V, Minero C, Vione D (2013) Photochemical transformation of atrazine and formation of photointermediates under conditions relevant to sunlit surface waters: laboratory measures and modelling. Water Res 47:6211-6222. https://doi.org/10.1016/j.watres.2013.07.038

Mostafa S, Rosario-Ortiz FL (2013) Singlet oxygen formation from wastewater organic matter. Environ Sci Technol 47:8179-8186. https://doi.org/10.1021/es401814s
Oppenlander T (2003) Photochemical purification of water and air: advanced oxidation processes (AOPs): principles, reaction mechanisms, reactor concepts, 1 st edn. Wiley-VCH, Weinheim

Passananti M, Temussi F, Iesce MR, Previtera L, Mailhot G, Vione D, Brigante M (2014) Photoenhanced transformation of nicotine in aquatic environments: involvement of naturally occurring radical sources. Water Res 55:106-114. https://doi.org/10.1016/j.watres. 2014.02.016

Schwarzenbach RP (2003) Environmental organic chemistry, Second edn. Wiley \& Sons, Inc., Hoboken

Shemer H, Sharpless CM, Elovitz MS, Linden KG (2006) Relative rate constants of contaminant with hydroxyl radicals. Environ Sci Technol 40:4460-4466. https://doi.org/10.1021/es0602602

Silva MP, Mostafa S, Mckay G, Rosario-Ortiz FL, Teixeira ACSC (2015) Photochemical fate of amicarbazone in aqueous media: laboratory measurement and simulations. Environ Eng Sci 32:730-740. https:// doi.org/10.1089/ees.2015.0127

Svanfelt J, Erikson J, Kronberg L (2010) Analysis of thyroid hormones in raw and treated waste water. J Chromatogr A 1217:6469-6474. https://doi.org/10.1016/j.chroma.2010.08.032

Svanfelt J, Erikson J, Kronberg L (2011) Photochemical transformation of the thyroid hormone levothyroxine in aqueous solution. Environ Sci Pollut Res 18:871-876. https://doi.org/10.1007/s11356-0110450-3

Van der Walt B, Cahnmann HJ (1982) Synthesis of thyroid hormone metabolites by photolysis of thyroxine and thyroxine analogs in the near UV. Proc Natl Acad Sci U S A 79:1492-1496

Vione D, Das R, Rubertelli F, Maurino V, Minero C, Barbati S, Chiron S (2010) Modelling the occurrence and reactivity of hydroxyl radicals in surface waters: implications for the fate of selected pesticides. Int J Environ Anal Chem 90:260-275. https://doi.org/10.1080/ 03067310902894218

Vione D, Maddigapu PR, Laurentiis ED, Minella M, Pazzi M, Maurino V, Minero C, Kouras S, Richard C (2011) Modelling the photochemical fate of ibuprofen in surface waters. Water Res 45:6725-6736. https://doi.org/10.1016/j.watres.2011.10.014

Vione D (2014) A test of the potentialities of the APEX software (Aqueous Photochemistry of Environmentally occurring Xenobiotics). Modelling the photochemical persistence of the herbicide cycloxydim in surface waters, based on literature kinetic data. Chemosphere 99:272-275. https://doi.org/10.1016/j.chemosphere. 2013.10.078

Zacarías VHR, Velázquez Machuca MA, Montañez Soto JL, Pimentel Equihua JL, Vallejo Cardona AA, López Calvillo MD, Venegas González J (2017) Hydrochemistry and emerging pollutants in urban industrial wastewater in Morelia, Michoacán, Mexico. Rev Int Contam Ambient 33:221-235. https://doi.org/10.20937/RICA. 2017.33.02.04 